\title{
Introduction: International Leadership in an Age of American Retreat, Chinese Return and Global Urgency
}

\author{
Ole Wæver $^{1}$ (D) Zhimin Chen ${ }^{2}$
}

Published online: 13 November 2017

(C) Fudan University and Springer Nature Singapore Pte Ltd. 2017

Donald J. Trump should be thanked for triggering this and the next special issue on international leadership. We cannot bring ourselves to outright dedicate the two issues to him, but he did get us started on the project. With the election in November 2016 of a US President with a highly dismissive attitude to international cooperation and a transactionalist policy approach unlikely to form the basis for leadership, the question posed itself: who then, if any? After US leadership, should we expect a general 'global leadership vacuum' (Solana 2017), intensified conflict over leadership, or is it more likely that as the US steps back, others will step forward?

China has been elevated to the position of global leader in many critical comments after various moves by Trump, often as a way to taunt his policies as selfdefeating, harmful to the US and "making China great again". China's President Xi Jinping felt obliged to move forward to address the leadership vacuum. In particular, his keynote address to the World Economic Forum in Davos on 17 January 2017 was noted for its full endorsement of globalization and a promise of China trying to become the guardian of global cooperation. Forbes entertained the headline "Communist China Is Now The Leader Of The 'Free Trade' World". 1

A particularly important Trump decision, the declaration that the US will pull out of the Paris agreement on climate action, triggered somewhat more varied interpretations about leadership effects. The dominant interpretation is that US

\footnotetext{
${ }^{1}$ https://www.forbes.com/sites/kenrapoza/2017/01/24/communist-china-is-now-the-leader-of-the-freetrade-world/\#3bdcee8521e0.

Ole Wæver

ow@ifs.ku.dk

Zhimin Chen

zhmchen@fudan.edu.cn

1 Department of Political Science, University of Copenhagen, Copenhagen, Denmark

2 School of International Relations and Public Affairs, Fudan University, Shanghai, China
} 
leadership is no longer mandatory on such matters and, therefore, this US decision will kill neither the Paris agreement nor climate cooperation in general. However, some commentators stressed - as on the previous issue- how this would strengthen China geopolitically due to both the gains from leadership status and benefits from spearheading the clean technology of the future. The respected British newspaper 'The Guardian' ran this headline and sub-title: "Trump's order signals end of US dominance in climate change battle. Trump's climate blitzkrieg is unlikely to herald the end of civilization, but it risks US geopolitical dominance and could help 'make China great again'".

Others, however, emphasized that the Paris agreement was saved through joint leadership by China and the $\mathrm{EU}^{3}$ as expressed in their joint declaration almostagreed on 2 June 2017 (deformalized due to trade disagreements) and expressed in meetings of the G8 and G20 throughout 2017. This EU-China partnership in turn prompted different interpretations: is this the new dynamic duo in world politicsor is it rather the fact that it is an ad-hoc alliance that is the point? The latter interpretation was reinforced by the 6 July 2017 agreement between the EU and Japan on bilateral trade. Meanwhile, China's acceleration and formalization of the Belt and Road Initiative (BRI) points more in the direction of cooperation promoted by a single power. Cases and complexities like these invite a more general, thorough and systematic investigation of global leadership, which the two consecutive special issues aspire to move towards: the first issue deals with the general discussions about international leadership and global governance; and the next one will focus on international leadership and the role of China.

"Leadership" is not a phenomenon that has attracted an enormous amount of focussed attention in the discipline of International Relations (IR). Simplifying a bit, scholars have approached it from two starting points, the traditional two privileged reference points in IR: powerful states and important individuals. From the first starting point emanates a tradition of testing how much leadership can be stretched in relation to power. The starting point is that with power comes often an increased possibility to lead; and some extreme versions of structural realism come close to reducing leadership to an expression of power. Most IR analyses of leadership, however, assume both that power is an important basis for leadership and that the relationship is complex, contingent and non-linear. This has produced studies for example of how great power attempts to lead have failed, and instances where small states have been able to exert international leadership. A famous article in this tradition of 'also power but not only' is cited by several contributors to this special issue: Oran Young's (1991) article "Political Leadership and Regime Formation" (see also Young 1994). Young distinguishes between three types of leadership: structural, entrepreneurial, and intellectual. The first, structural kind translates power into leadership; the second entrepreneurial one uses negotiating skills to broker interests and build consensus on an institutional arrangement, and the third, intellectual type delivers a way of thinking about the issue that facilitates regime

\footnotetext{
${ }^{2}$ https://www.theguardian.com/environment/2017/mar/28/trump-climate-change-executive-order-usdominance-china.

${ }^{3}$ Eg. http://www.bbc.com/news/science-environment-40106281.
} 
formation. Because the three types in practice are intermingled, a key factor becomes the interaction among individual leaders. This is the second pole of theorizing on leadership: what qualities and actions can make an individual effective as leader.

As evidenced by the articles in this double issue, it is possible to place the emphasis variably on leadership focused at the state level or at the level of individuals - or thirdly to fuse the two.

State centred analyses discuss - as in the opening paragraphs of this article-first of all the current situation in terms of which states are candidates for what leadership roles: will China become the leader globally, or only one of them or only regionally? Will the EU? Will leadership generally shift to different constellations of actors including international organizations, states, movements and NGOs (as often implied in the terminology of 'governance')? The articles by Wæver, Breslin, Mortensen, Kristensen, Chen et al., Cooper, Pu, Wang, Lin and Sun in these two issues mostly take this approach, i.e. discussing the conditions and effects of leadership by particular units, be they specific states or other actors. In contrast, the articles by Morton, Zhang and Beeson go more into detail on individual leaders who have played a key role in past and present attempts to forge international cooperation. In particular, the paper by Zhang looks in detail at the personal qualities of Trump compared to Obama.

A third possible approach views these two levels as inherently linked, most interestingly in the manner where the personal qualities of the national leaders are an important element in constituting state power, i.e. only if the leaders have a certain moral quality can the state also become powerful and a true leader. Notably, this argument is mostly made by Chinese contributors to the two issues. This is in some sense surprising given that it is solidly entrenched in key philosophical traditions in both Western and Chinese philosophy. However, it seems to have become marginalized in current Western scholarship, so that the point is made most strongly in the present issues by Chinese contributors like Chen, Zhou and Wang in the second issue (volume. 3:1; 2018), and in striking fashion Zhang makes an argument of this kind by way of a re-reading of Morgenthau and Western realist theory. In Western thought, it was central from at least Socrates onwards that personal striving for an excellent character was necessary for achieving true results including those in politics. All the way along to even a presumably arch-realist figure like Machiavelli, there is still some complex relationship between personal morality and political achievement through the concept of virtue, even if (or actually because) the overall project of Machiavelli to some extent was to relax that link (Machiavelli 2009). Similarly, in Chinese political thought, as argued in relation to IR by Yan Xuetong, even — or in his view actually: particularly_a realist should pay heed to pre-Qin Chinese thinkers who argued that the highest form of international leadership can only be achieved by a state where the leaders practice humane authority, neither hegemony nor tyranny (Yan 2011). This 'third way' analysis is most clearly represented in the current set of two special issues by Zhang's article in this the first issue focusing on the US, and not least by the article (in the next issue; stay tuned!) by Chen, Zhou and Wang, which explores that 
possibility that China can devise a form of leadership that is sufficiently different from that of the US to avoid repeating some of its most momentous mistakes.

Instead of re-inventing the wheel, one is often well advised to consider if another discipline might have done the work already. Beyond the possibilities of going into general philosophy or various branches of sociology, which is too complex for the current setting, the most likely operational candidate would be writings on management and business. ${ }^{4}$ One of the most influential models here is the so-called "four frame model" that contrasts structural, human resource, political and symbolic leaderships (Bolman and Deal 2013). This is not dramatically different from the typology of Young, and generally, 'leadership' seems to be an area where different fields have reached relatively similar conclusions. For instance, a key element in management studies of leadership is the role of leaders and followers, as emphasized in IR by Breslin and actualized in his article in the current issue. An important argument made in the management literature on this point is the role of followers 'authorising' leaders to lead, not only accepting a concrete initiative (Heifetz 1994). This resonates with parts of the IR literature that appear in several of the articles here but could deserve to be more fully explored: great powers are often thought of as the 'leaders' internationally, but even in the more 'social' take on great powers by the International Society approach of the English School, most of the emphasis is on how the great powers regulate collectively amongst themselves who they admit to the club of great powers (Bull 1977) - less has been done so far on how the non-great powers react variably to the idea of great powers in general and to the 'authority' of specific great powers to be great.

The articles in these two issues each contains numerous, nuanced arguments and therefore should be read in their full length, not grasped by a summary. Nevertheless, we would like to offer a one liner for each. In the first article of this special issue on "International Leadership and Global Governance," Ole Wæver argues: the structure of the international system should prepare us for a general deficit of leadership and occasional ad-hoc coalitions driven by existential fears of global dangers and/or a possibility for a nation/polity to build an international role through leadership, as we saw with the EU and China in relation to the climate. Katherine Morton both reinforces and challenges the analysis from the first article by emphasizing the importance for the leadership candidates of custodial leadership on the main global challenges while pointing to a less state-centric analysis including more emphasis on individual leaders, bringing some hope for collaborative leadership. Shaun Breslin extends his previous analysis of the relationship between leadership and followership pointing to an increased role for functionalist dynamics in a "non-polar" world of fragmented and shifting leadership. Biao Zhang takes us back to that last, possibly departing superpower, the US, and uses a theory developed in the US, Morgenthau's realism, to present a checklist of qualities necessary for leadership and predicts how Donald Trump's presidency is likely to contribute to chaos and a leaderless world. Jens Ladefoged Mortensen shifts the focus to International Political Economy, more precisely the current trading (dis)order, where it is shown how the domestic sources of leadership

${ }^{4}$ Thanks to Suzi Lyng Hansen for helpful advice on this. 
are becoming increasingly decisive and how institutional leadership is giving way to instituationalized leadership in the sense of control over a particular site. Conflicts between the US and the EU are at the centre of current global competition between different formats. Peter Marcus Kristensen moves the centre of attention to the world of scholars, analysing the internal debates among American observers and scholars of IR, re-reading their debates on the changing global order as expressions not only of disagreements on the empirical object of analysis but rather as political moves in a debate, which shows that beneath seemingly neutral terms of leadership and 'a leaderless world' are often criteria for 'good' leadership that really means US leadership, and thus Chinese leadership is really not able to serve as a solution, only as part of the problem, in this academic set-up. Finally, Mark Beeson draws together many of the questions that have been addressed in the issue by way of a discussion of the possibility for Asia-Pacific leadership in a period defined by both US reluctance under Trump and Chinese strengthening, while it still remains an open question whether ultimately China has the will and ability to develop a sustained leadership in Asia.

In the next special issue of this journal, titled "International Leadership and the Role of China, volume 3:1 in 2018, the conversation continues. The first article by Zhimin Chen, Guorong Zhou and Shichen Wang zooms in on the question that the debate in the previous article pointed towards: Can and will China take on a leadership role in the world, and if so can it be of a different kind from what has been practiced especially by the US? The tentative answer based on both theoretical and empirical analysis (regarding the BRI) points to a possible form of facilitative leadership that is more collective, attractive, win-win and empowering. Andrew Cooper and Zhang Yanbing offer a somewhat more conflictual picture of Chinese leadership, now focused on globally oriented organizations. Their key argument is that China has practised a dualistic strategy as both insider and outsider in the global system, becoming both a core member of the 'hub' forum the G20 and cultivating a number of parallel non-Western institutions like the BRICS and BRI. This dualism serves a number of purposes both internationally and domestically, but it also presents some important questions in relation to the kind of leadership that China might offer in the emerging international system. Xiaoyu Pu furthers the exploration of Chinese international leadership, now with the central contrast being regional versus global and with the concept of status as a key analytical device. The analysis points to severe limits to China becoming a solo leader, both regionally and especially globally, and fortunately also points to ways that status is not always relative and competitive and, therefore, how it is possible to realize joint gains through joint leadership. Jue Wang continues the study of actual Chinese leadership, in this case through collaboration with the IMF. This analysis too points to limits to future leadership by demonstrating how the actual increase in Chinese influence has been conditioned by specific circumstances in relation to both the IMF and the US, where China has had limited effects when these conditions were not fulfilled. Stefano Burzo and Xiaojun Li move the analytical focus back to a comparative look at the US and China, bringing public perceptions into the picture. The unique material in the form of parallel surveys presents a number of surprises, potentially (with a number of methodological caveats) pointing to an intriguing scenario where 
Americans are actually more open than expected to divided leadership, while the Chinese might be hampered by a too monolithic conception of leadership as an allor-nothing thing. Finally, Sun Xuefeng continues the bi-focal look on US-Chinese approaches, now with East Asian regional security as a concrete case. Based on the concept of a 'rise dilemma' for China, the article shows how the increasing external security pressure China has faced has been handled by a state-by-state approach contingent on the more institutionalized US security system. The interaction between this Chinese strategy of strategic hedging and varying conditions among the different neighbours for relating differently to China produces a complex and nuanced pattern of strategic relationships that defy any easy picture of one power leading or the other. Finally, Pippa Morgan from Fudan and Peter Marcus Kristensen from Copenhagen round off the second issue with another joint article taking stock and pointing into the future, more convincingly and appropriately than the two of us can do, given that their generation will play a bigger role and has a greater stake in the future-including the future of global leadership on global challenges.

This is a fitting conclusion to the combined effort of all the authors contributing to these two issues as well as various others involved with and contributing to both the workshop and the publication. The international system is changing in important ways as a combined effect of system level broad processes and domestic peculiarities especially in the US and China, some of these coming down to the character of individual leaders (and actually-not-really-leaders).

Leadership can be good. Often this appears differently to those that lead and those who are led (and in our day-jobs one of us is mostly on one side of that distinction, while the other is on the opposite side; hopefully these have made us sensitive to the full picture). In international affairs, it is widely accepted that quite often leadership is necessary because the basic structure is decentralised, authority and power are anchored at the national level and cooperation is only something that is achieved by effort, not automatically. Arguably, the world will face some dramatic collective dangers in the coming decade-ranging from climate change and other technology centred dangers like superhuman machine intelligence over vulnerabilities to the global economic order to parallel processes of domestic discontent that erupt into populist self-centredness. As the stakes are growing and the system is simultaneously becoming more decentralised, any attempt to exercise leadership is likely to become increasingly controversial and contested-no format will 'grow' forth as a natural process. However, to the extent that several of these global dangers are at least in broad terms seen as shared concerns (even if the precise terms are not agreed upon), there will probably be an increasing reward in terms of social acceptance (authorization) of leaders who are widely perceived to do something about these issues. Paradoxically, we might therefore end up concluding that 'international leadership' in the coming years will be less about the international and less about who are the leaders. That is: self-referential concerns about who leads what regional or global institution or constellation will become less important, and outcomes less decided by purely interstate issues about who is willing to accept whom to be how powerful in their relationship, and more determined by who authorises whom to lead on what issues because this is 
perceived to actually work. In the future, to be seen as promoting actual solutions and be willing to deliver one's own part of the effort will increasingly decide who comes to embody the leadership of global governance.

\section{References}

Bolman, LG., and Terrence E. Deal. 2013. Reframing Organizations: Artistry, Choice, and Leadership, 5th ed. San Francisco: Jossey-Bass.

Bull, H. 1977. The Anarchical Society. A Study of Order in World Politics. New York: Columbia University Press.

Heifetz, RA. 1994. Leadership Without Easy Answers. Cambridge: Harvard University Press.

Machiavelli, N. 2009. Discourses on Livy. Translated by Julia Conaway Bondanella and Peter Bondanella. Reissue edition. Oxford; New York: Oxford University Press (original Italian publication 1531).

Solana, J. 2017. The Global Leadership Vacuum. Project Syndicate. September 19. https://www.projectsyndicate.org/commentary/trump-global-leadership-vacuum-by-javier-solana-2017-09. Accessed 27 Oct 2017.

Yan, Xuetong. 2011. Ancient Chinese thought, modern Chinese power. Princeton: Princeton University Press.

Young, OR. 1991. Political leadership and regime formation: On the development of institutions in international society. International Organization 45 (3): 281-308.

Young, OR. 1994. International Governance: Protecting the Environment in a Stateless Society. Ithaca: Cornell University Press.

Ole Wæver, Ph.D., Dr.h.c. is professor of International Relations at the Department of Political Science, University of Copenhagen, and Director of the Center for Resolution of International Conflicts. He was the founder and from 2008 to 2013 the director of Centre for Advanced Security Theory. Among his main books are Security: A New Framework for Analysis (with Barry Buzan and Jaap de Wilde, Lynne Rienner 1988, Chinese 2002, Czech 2006); Regions and Powers: The Structure of International Security (with Barry Buzan, Cambridge University Press 2003; Chinese and Persian translations 2009); International Relations Scholarship Around the World (ed with Arlene B. Tickner, Routledge 2009); Climate change: Global Risks, Challenges \& Decisions (with Katherine Richardson et al. Cambridge University Press 2011).Email: ow@ifs.ku.dk.

Zhimin Chen, Ph.D. is a Changjiang Scholar and professor in international politics at the School of International Relations and Public Affairs, Fudan University, associate vice president of Fudan University. He also holds a Jean Monnet Chair in European Foreign Policy. Corresponding: zhmchen@fudan.edu.cn, School of International Relations and Public Affairs, Fudan University, 220 Handan Road, Shanghai, 200433, China PR. 